\title{
aniki
}

Revista Portuguesa da Imagem em Movimento

Portuguese Journal of the Moving Image

\section{Um Possível Panorama: A mostra "O Mundo Visto e Sonhado" (2021) e a memória do cinema realizado no Espírito Santo}

\section{Luana Cabral}

Instituto de Arte e Comunicação Social, Universidade Federal Fluminense luanam.cabral@gmail.com

https://orcid.org/0000-0001-5252-957X

Em memória de Orlando Bomfim Netto (1941-2021)

Realizada ao longo do mês de maio de 2021, a mostra O Mundo Visto e Sonhado: Uma coleção de filmes do Espírito Santo reuniu obras produzidas durante os quase cem anos de existência do chamado "cinema capixaba". ${ }^{1}$ A mostra é uma iniciativa do CineLimite, ${ }^{2}$ sediado duplamente na cidade de Nova York (Estados Unidos da América) e no estado brasileiro da Bahia. Além dos filmes, o programa reuniu entrevistas, artigos escritos por pesquisadores e pesquisadoras do tema e ensaios audiovisuais. O conjunto de nove curtas-metragens selecionado apresenta desde as primeiras imagens em movimento a registarem o estado de Espírito Santo, produzidas pelo pioneiro Ludovico Persici e organizadas em Cenas de família (1926-1929), ${ }^{3}$ até o contemporâneo Das águas que passam (2016), documentário dirigido pelo cineasta Diego Zon.

\footnotetext{
${ }^{1} \mathrm{~A}$ expressão refere-se à produção cinematográfica realizada no estado do Espírito Santo, localizado na região sudeste do Brasil.

${ }^{2}$ Segundo informações disponíveis em seu próprio site, CineLimite é uma organização arte-media sem fins lucrativos, dedicada à expansão da presença do cinema brasileiro nos Estados Unidos e em outros países.

${ }^{3}$ Título atribuído ao material resultante da restauração e digitalização empreendida entre 2004 e 2010.
} 


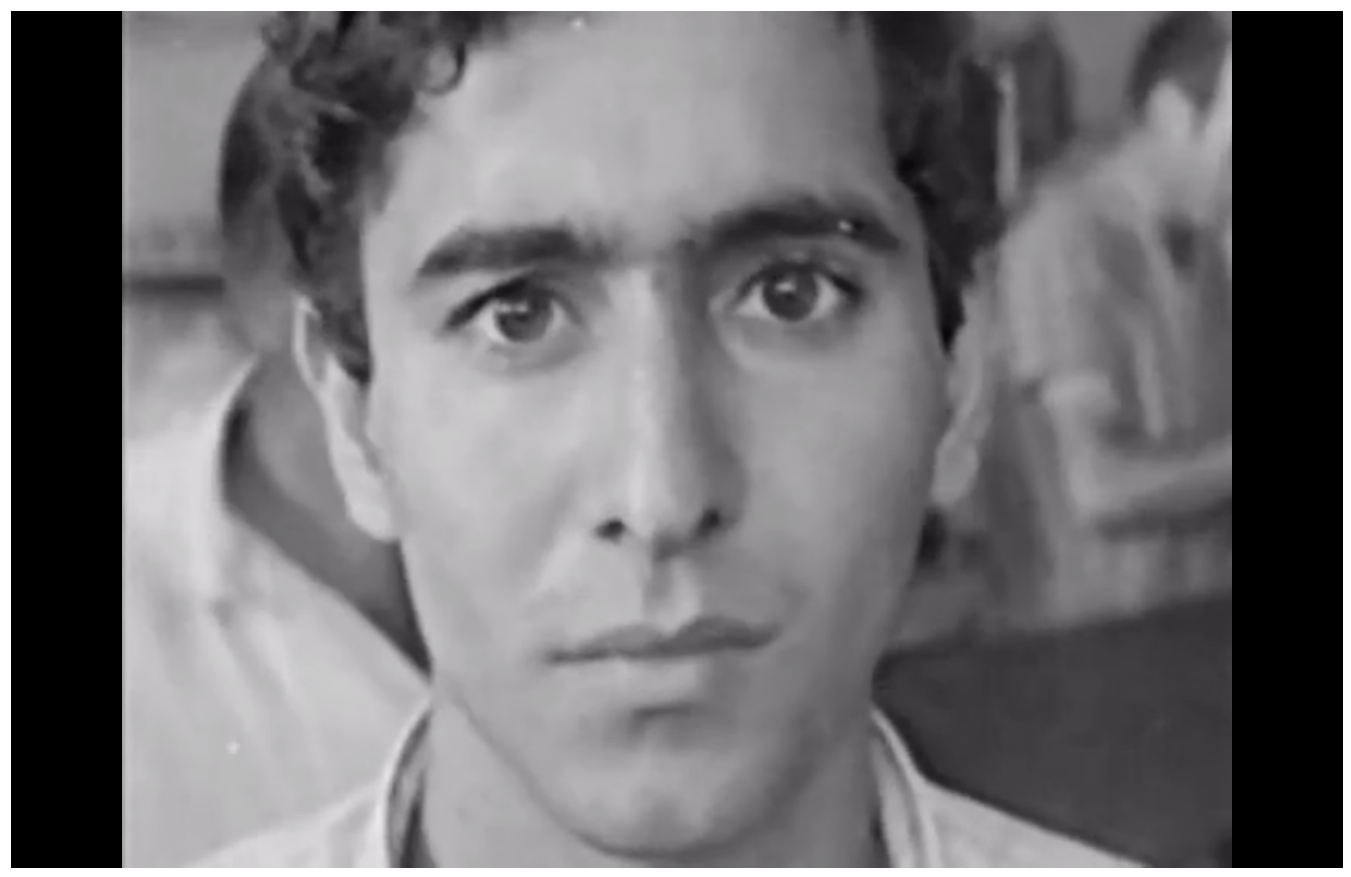

Imagem 1: O estudante nos encara. Still do filme Kaput (1967). | @ Ramon Alvarado.

Para compreender o pioneirismo da mostra, é preciso localizar o estado do Espírito Santo, de ontem e de hoje, no contexto brasileiro. Geograficamente situado na mesma região em que se localizam os dois maiores polos audiovisuais brasileiros, nomeadamente os estados do Rio de Janeiro e de São Paulo, o Espírito Santo possui uma trajetória cinematográfica muito mais próxima daquela observada em estados menores do Brasil, cujo desenvolvimento econômico se deu de forma distinta à dos estados mencionados e cujas capitais passaram por processos de modernização e urbanização tardios (Vieira Jr. 2021). Naturalmente, são esses os lugares que fogem às narrativas hegemônicas do cinema brasileiro, sustentadas pela numerosa produção cinematográfica realizada nas grandes capitais desde meados dos anos 1920 .

Como coloca Erly Vieira Jr. (2021), o cinema no Espírito Santo é caracterizado por sua inconstância - poderíamos dizer, tomando por empréstimo um termo utilizado por Viany (1993) e Bernardet (2007), que se trata de um cinema composto por "surtos de produção". Dessa forma, sua história não se organiza de maneira coesa e linear pelo menos até meados dos anos 1990, quando o surgimento de movimentos artísticos ligados à videoarte mudaria a cena cultural deste estado, especialmente de sua capital, Vitória. Nota-se que, a partir dos anos 
1990, algumas mudanças estruturais foram responsáveis pelo crescimento da produção audiovisual do estado, entre elas a criação de fomentos públicos regionais e a consolidação de entidades representativas, como a Associação Brasileira de Documentaristas e Curta Metragistas do Espírito Santo. ${ }^{4}$

A curadoria do produtor e cineasta capixaba Vitor Graize ${ }^{5}$ traz ainda Kaput (1967) e Ponto e vírgula (1969), dois exemplares do cinema amador capixaba, realizados no auge da ditadura militar brasileira, que integraram o chamado primeiro ciclo de curtas-metragens do Espírito Santo ou a "geração 60", como define Milson Henriques (2007), ator e à época integrante do movimento. Também realizado na década de 1960, há o documentário científico Cirurgia do coração no Espírito Santo (1964), obra singular na cinematografia do estado, recentemente digitalizado a partir do único material existente, preservado pelo seu diretor Ramon Alvarado. O cinema de Orlando Bomfim Netto, dedicado ao registo documental da cultura popular brasileira, está representado por Tutti tutti buona gente, propriamente buona (1975) e Ticumbi - Canto para a liberdade (1978). Já nos anos 1990 e 2000, com as ficções A lenda de Proitnier (1996) e No princípio era o verbo (2005), o conjunto se abre para um novo contexto de produção e circulação de filmes capixabas no Brasil e no mundo, marcado pelo aumento e pela diversificação da produção cinematográfica nos formatos de curta e média-metragem.

Parte dos filmes apresentados no programa teve a sua circulação possibilitada graças a recentes processos de restauração e digitalização, que interromperam décadas de inacessibilidade deste material. É o caso de Cirurgia do coração no Espírito Santo (1964), um dos raros exemplares do gênero documentário científico que figuram na filmografia capixaba, cuja existência era conhecida, até a exibição da sua cópia digitalizada nesta ocasião, apenas por meio de referências orais e acadêmicas. Também são frutos de recentes digitalizações as cópias exibidas de Tutti tutti buona gente, propriamente buona (1975) e Ticumbi - Canto para a liberdade (1978). Os dois filmes integram um conjunto de sete obras do cineasta Orlando Bomfim Netto recuperadas

\footnotetext{
${ }^{4}$ A Associação Brasileira de Documentaristas e Curta Metragistas do Espírito Santo (ABD) foi fundada em 2000, numa articulação liderada pelo cineasta Orlando Bomfim Netto. A ABD Capixaba é hoje a principal entidade representativa do setor audiovisual do Espírito Santo.

${ }^{5} \mathrm{O}$ programa traz um texto inédito do curador sobre o movimento de cinema amador capixaba.
} 
pelo projeto de preservação audiovisual Acervo Capixaba, conduzido pela produtora Pique-Bandeira Filmes. Eles foram exibidos anteriormente na retrospectiva "Imagens para a Liberdade" (2018), que gerou a publicação de um catálogo homônimo (Dieuzeide e Graize 2018).

Cenas de família (1926-1929) é resultado de uma pesquisa iniciada a partir do relato de José Mussi Neto a respeito do trabalho exercido pelo avô nas filmagens realizadas por Ludovico Persici no Espírito Santo desde os anos 1930 (Osório 2007, 36). A localização do material permitiu sua restauração e digitalização em 2010, cerca de 80 anos após a fixação das imagens. Também a presença de Kaput (1967) é fruto dos esforços empreendidos por Nenna e Marcos Valério em sua recuperação, culminando na produção de uma cópia em vídeo em 1991 (Osório 2007, 71). Notamos, assim, a existência de um contexto que circunda a mostra $O$ Mundo Visto e Sonhado, caracterizado pela existência de um desejo em comum: a preservação histórica do audiovisual capixaba, voltada especialmente à difusão de obras pouco conhecidas pelo grande público. A partir das iniciativas anteriormente mencionadas, percebemos que há um crescente interesse pela circulação dessas obras, cujo conhecimento e divulgação ajudam a reconstituir a pequena história do cinema realizado no Espírito Santo e celebram a preservação de sua memória.

É curioso perceber como alguns dos filmes programados também trazem consigo discussões ou percepções acerca da memória, especificamente aplicada ao seu aspecto coletivo e à amplificação de seu significado no contexto social brasileiro. Kaput (1967) (Imagem 1) e Ponto e vírgula (1969), realizados em plena ditadura militar, traduzem em sua linguagem as angústias de parte da juventude brasileira nos anos 1960, diante do contexto político e da atmosfera repressiva na qual se encontrava o país, e que acabaria por marcar aquela geração. Como coloca Henriques, os filmes da época eram, em sua maioria, de protesto, "inspirados no film noir, na nouvelle vague e no neorrealismo italiano" (2007, 57); para fazê-los, era necessário ter coragem devido à intensa perseguição exercida pelas forças repressoras da censura e pela inviabilidade financeira da atividade, muito custosa e nada lucrativa (Henriques 2007, 57). Afinal, os filmes de Paulo Torre e Luiz Tadeu Teixeira nos lembram que o cinema deste pequeno estado também documenta as agruras de um Brasil autoritário, retrógrado e violento que teima em não desaparecer. Assisti-los quando o país se encontra 
novamente sequestrado por forças políticas desse mesmo espectro é, no mínimo, uma lembrança de que temos um longo passado pela frente.

Nesse sentido, ao olharmos com atenção a obra de Orlando Bomfim Netto somos convidados e convidadas a percebê-la como uma lembrança do exercício infindável de preservação cultural potencializado pelo cinema. Filmes como Ticumbi - Canto para a Liberdade (1978) são de fato relicários, pequenos gestos de dedicação à salvaguarda daquilo que se considera precioso no contexto de uma comunidade e vital na sua memória. Ao mesmo tempo, a realização de Das águas que passam (2016) (Imagem 2) antecede quase imediatamente o maior crime ambiental da história do Brasil, ocorrido em 5 de novembro de 2015 na cidade de Mariana, no estado de Minas Gerais, quando uma barragem da mineradora Samarco se rompeu. ${ }^{6}$ Este filme torna-se, nas palavras do seu diretor, "um registo ainda mais importante de se preservar nestes tempos de apagamento das memórias" (Pestana e Plotnick 2021). Acrescentemos que, no caso da morte de um rio e daquilo que se põe à sua volta, as relações estabelecidas entre memória e vida se apresentam como urgentes, incontornáveis, quase insuperáveis.

Não seria possível sintetizar uma história que ainda não foi contada. Por essa razão, mais do que um panorama geral, O Mundo Visto e Sonhado afirma-se como um atestado sobre a vontade constantemente renovada de busca, construção e preservação das memórias inscritas na produção audiovisual capixaba, observadas não tão somente nas ações de preservação que possibilitaram a sobrevivência dos filmes exibidos pela mostra, mas também entrelaçadas à existência de algumas dessas obras, que de forma intencional ou não, acabaram por registrar pedaços importantes da história do estado e do país. Relegada à sua origem tardia e ao papel marginal conferido às cinematografias menores, a produção audiovisual do Espírito Santo ainda carece de estudos mais profundos e iniciativas de recuperação, sobretudo da materialidade dos filmes perdidos, inacabados ou esquecidos. De maior importância, talvez, sejam ainda os filmes desconhecidos, aqueles que a memória coletiva e o pensamento hegemônico não conseguiram compreender e

\footnotetext{
${ }^{6}$ Após o rompimento da barragem, a lama tóxica contaminada de rejeitos espalhou-se pela cidade e por seu entorno, causando a morte de dezenove pessoas. Os rejeitos contaminaram o Rio Doce, chegando até o litoral capixaba, causando pelo caminho a intoxicação da água, a morte de peixes e animais e destruindo a fonte de renda e subsistência das comunidades em seu entorno (Tokarnia 2020).
} 
assimilar, cuja descoberta, apostamos, deve incluir tópicos interessantes para a "reconstituição" de uma história perdida ou para a formulação de novas histórias.

O revelar desses arquivos dá a ver a complexa gama de transformações políticas, sociais e ambientais que nos trouxeram até aqui, ocorridas desde que foram produzidos os primeiros registros em imagem e som desta terra, destas águas e desta gente. A ameaça a este patrimônio ainda semi-estabelecido é iminente. Enquanto seus defensores e suas defensoras lutam para preservá-lo, e mesmo enquanto este texto está sendo escrito, no dia 29 de julho de 2021, um incêndio de grandes proporções atinge um dos galpões da Cinemateca Brasileira, maior acervo cinematográfico da América Latina. ${ }^{7}$ Embora o risco de um episódio como esse tenha sido publicamente denunciado como um “crime anunciado" pelos trabalhadores da instituição, e, portanto, não seja tão surpreendente, são assustadoras as tentativas sistemáticas de apagamento histórico que culminam nesta tragédia - sem que pudéssemos agir, de uma hora para a outra, o patrimônio que pensávamos construir já se tornou uma densa fumaça escura que cobre a cidade de São Paulo. Além dos escombros, ficam as lacunas e incertezas ao olharmos para o passado; no caso de cinematografias nãohegemônicas como a do Espírito Santo, voltamos alguns passos na descoberta e na recuperação de materiais e informações essenciais para a construção efetiva de nossa memória.

\footnotetext{
${ }^{7} \mathrm{O}$ incêndio é o quinto a ocorrer na Cinemateca Brasileira desde a sua fundação, no ano de 1946. O episódio ocorre após a administração da instituição ter sido passada ao governo brasileiro, do presidente Jair Bolsonaro, em agosto de 2020, quando todos os funcionários da instituição foram demitidos e seus prédios foram fechados. A situação se manteve durante a escrita deste texto, prolongando-se por mais de um ano sem grandes avanços, mesmo após o incêndio e as inúmeras e contundentes denúncias feitas pelos trabalhadores da Cinemateca, por diversos e diversas representantes do setor audiovisual brasileiro e pela sociedade civil.
} 


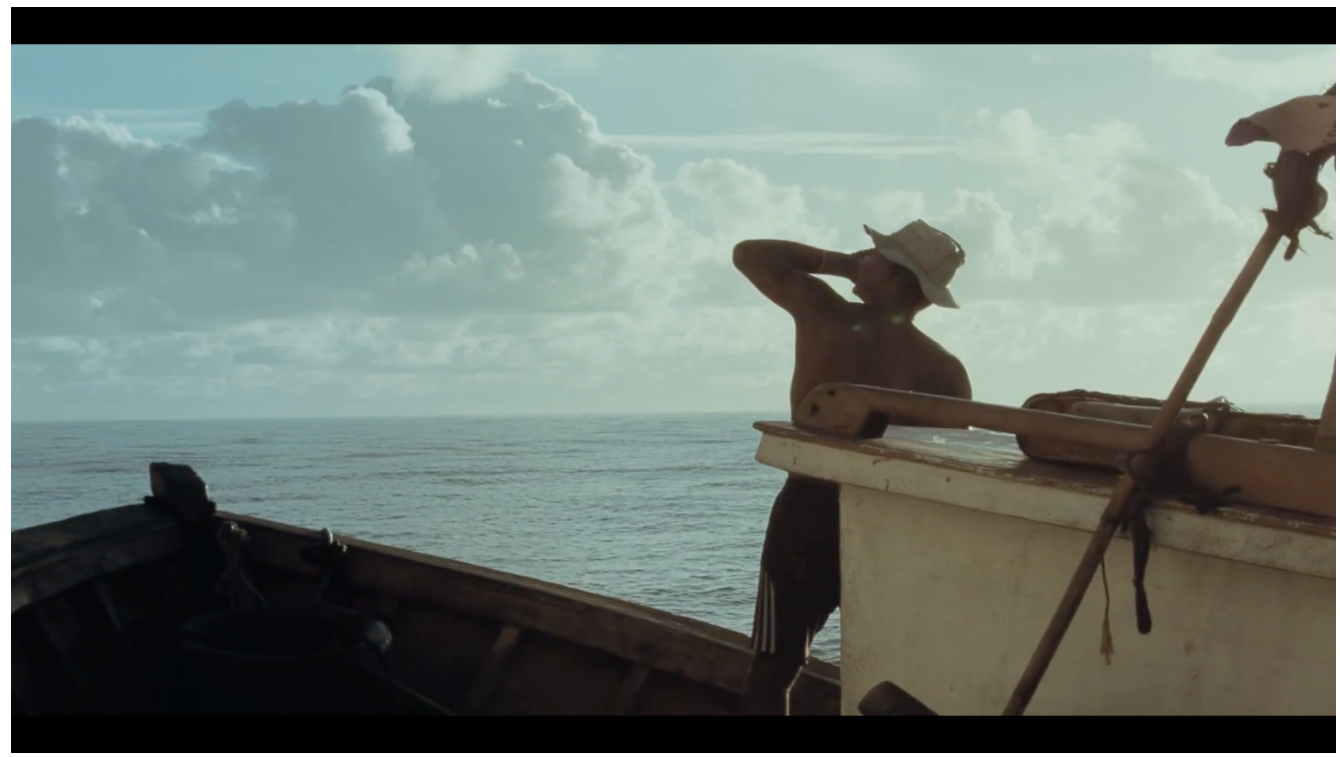

Imagem 2: Still de Das Águas que Passam (2016). | ( C Patrick Tristão.

\section{Referências}

Bernardet, Jean-Claude. 2007. Brasil em tempo de cinema: ensaio sobre o cinema brasileiro de 1958 a 1966. São Paulo: Companhia das Letras.

Dieuzeide, Maria Inês e Graize, Vitor. 2018. “Apresentação.” Em: Imagens para a liberdade: retrospectiva Orlando Bomfim, netto, editado por Maria Inês Dieuzeide e Vitor Graize, 9-11. Vitória: Centro Cultural Sesc Glória.

Graize, Vitor. 2021. “Um Mundo Visto e Sonhado." Trad. Gustavo Menezes. CineLimite (website), maio 22, 2021. Último acesso a 01 de julho de 2021. https://www.cinelimite.com/post/ummundo-visto-e-sonhado.

Henriques, Milson. 2007. "Geração 60 e o movimento do cinema amador." Em: Catálogo de filmes: 81 anos de cinema no Espírito Santo, organizado por Carla Osório, 54-59. Vitória: ABD\&C/ES.

Osório, Carla. 2007. Catálogo de filmes: 81 anos de cinema no Espírito Santo. Vitória: ABD\&C/ES.

Pestana, Matheus e Plotnick, William. 2021. "Diego Zon sobre Das Águas que Passam.” CineLimite (website). Maio 13, 2021. Último $\begin{array}{llllll}\text { acesso } & \text { a } & 02 & \text { de } & \text { julho de }\end{array}$ 
https://www.cinelimite.com/post/diego-zon-sobre-das-aguasque-passam.

Tokarnia, Mariana. 2020. "Tragédia de Mariana faz 5 anos e população ainda aguarda reparações”. Agência Brasil. 29 de outubro de 2020. https://agenciabrasil.ebc.com.br/geral/noticia/2020-

10/tragedia-de-mariana-faz-5-anos-e-populacao-ainda-aguardareparacoes.

Viany, Alex. 1993. Introdução ao Cinema Brasileiro. Rio de Janeiro: Revan.

Vieira Jr., Erly. 2021. “Alguns apontamentos sobre a história do cinema produzido no Espírito Santo: dos primórdios ao início dos anos 1990." CineLimite (website). Maio 11, 2021. Último acesso a 01 de julho de 2021. https://www.cinelimite.com/post/algunsapontamentos-sobre-a-historia-do-cinema-produzido-noespirito-santo-dos-primordios-ao-inicio-dos-anos-1990.

\section{Filmografia}

A Lenda de Proitnier [curta-metragem, 16mm] Dir. Luiza Lubiana. S/ produtora, Brasil, 1995. 21 minutos.

Cenas de família [curta-metragem, 16mm] Dir. Ludovico Persici. S/ produtora, Brasil, 1926-1929. 19 minutos.

Cirurgia do coração no Espírito Santo [curta-metragem, 16mm] Dir. Ramon Alvarado. S/ produtora. Brasil, 1967. 7 minutos.

Das águas que passam [curta-metragem, digital] Dir. Diego Zon. Timing Z. Brasil, 2016. 23 minutos.

No princípio era o verbo [curta-metragem, 35mm] Dir. Virginia Jorge. Galpão Produções/Secretaria Estadual de Cultura-ES, Brasil, 2005. 18 minutos.

Kaput [curta-metragem, 16mm] Dir. Paulo Torre. S/ produtora. Brasil, 1967. 12 minutos.

Ponto e vírgula [curta-metragem, 16mm] Dir. Luis Tadeu Teixeira. S/ produtora, Brasil, 1969. 6 minutos.

Ticumbi - Canto para a liberdade [curta-metragem, 35mm] Dir. Orlando Bonfim Netto. Circus Produções Cinematográficas. Brasil, 1978. 20 minutos. 
Tutti tutti buona gente, propriamente buona [curta-metragem, $35 \mathrm{~mm}$ ] Dir. Orlando Bomfim Netto. Circus Produções Cinematográficas Brasil, 1975. 28 minutos. 